\title{
REGISTRO Y CARACTERIZACIÓN DE LAS POLÍTICAS PÚBLICAS EN MATERIA DE ACTIVIDAD FÍSICA, DEPORTE Y RECREACIÓN EN VENEZUELA (PERÍODO 1999-2014)
}

Recebido em: 14/07/2019

Aprovado em: 21/01/2020

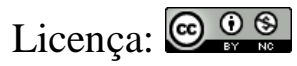

\author{
Alixon Reyes 1 \\ Universidad Adventista de Chile (UNACH) \\ Chillán - Chile
}

\begin{abstract}
RESUMEN: El presente trabajo tiene como propósito caracterizar las políticas públicas que, en materia de actividad física, deporte y recreación se desarrollaron en la República Bolivariana de Venezuela en el período que abarca los años 1999 y 2014. Para ello se ha privilegiado la investigación retrospectiva, usando el método histórico a través de la técnica documental en función de materiales como memorias y cuenta de los ministerios responsables, páginas web oficiales de instituciones del Estado, declaraciones de responsables como ministros, decretos, leyes, balances de gestión, documentos elaborados por asesores del Estado en el período señalado. Se ha encontrado que las políticas públicas en materia de actividad física, deporte y recreación en Venezuela tienen una reorientación si se comparan con las que venían en desarrollo antes del período señalado entre 1999 y 2014, se generan políticas en campos como la recreación que hasta 1999 jamás se habían desarrollado, entre otros elementos. Finalmente, se encuentra que existen elementos necesarios para corregir durante el proceso de desarrollo y puesta en ejecución.
\end{abstract}

PALABRAS CLAVE: Política Pública. Actividad Motora. Deportes. Recreación.

\section{REGISTRATION AND CHARACTERIZATION OF PUBLIC POLICIES ON PHYSICAL ACTIVITY, SPORTS AND RECREATION IN VENEZUELA (PERIOD 1999-2014)}

ABSTRACT: The purpose of this paper is to characterize the public policies that, in the field of physical activity, sports and recreation, were developed in the Bolivarian Republic of Venezuela in the period covering the years 1999 and 2014. For this, retrospective research has been privileged, using the historical method through the documentary technique based on materials such as reports and account of the responsible ministries, official websites of State institutions, statements of responsible ministers, decrees, laws, balance sheets management, documents prepared by State advisors in the period indicated. It has been found that public policies on physical

\footnotetext{
1 Pedagogía en Educación Física; Núcleo de Investigación en Ciencias de la Motricidad Humana; Grupo de Investigación AFSYE: Universidad Adventista de Chile, Chillán, Chile. Grupo de Investigación en Educación Física y Salud: Instituto Superior de Formación Docente Salomé Ureña, Recinto Luis Napoleón Núñez Molina, República Dominicana.
} 
activity, sports and recreation in Venezuela have a reorientation if compared to those that were in development before the period between 1999 and 2014, policies are generated in fields such as recreation until 1999 they had never developed, among other elements. Finally, it is found that there are necessary elements to correct during the process of development and implementation.

KEYWORDS: Public Policy. Motor Activity. Sports. Recreation.

\section{Introducción}

Presentar un análisis histórico de la política pública en materia de actividad física, deporte y recreación en la República Bolivariana de Venezuela, representa un esfuerzo que puede generar encuentros y desencuentros entre los especialistas en estos campos en el país, más aún cuando temas asociados al contexto político venezolano levantan hoy, tanta discusión. No obstante, el registro de investigaciones desarrolladas en el país devela casos de pesquisas que ofrecen conclusiones importantes para quienes nos preocupamos por estos campos. Altuve $(2008,2011,2012)$ es uno de los investigadores que más se ha preocupado por desarrollar metodologías de aproximación a los análisis de políticas públicas en materia de actividad física, deporte y recreación en Venezuela. Hay casos de investigadores como Carlos Felice Castillo, Jesús Elorza, Wulian Moreno, quienes también han presentado análisis situacionales en relación con aspectos de la política deportiva; hablamos de municipalización del deporte, administración y gerencia deportiva, legislación, entre otros. Si bien es cierto que se han realizado investigaciones en recreación, tenemos que, en lo investigado en Venezuela predomina una tendencia positivista e instrumental (TABARES et al. 2014), tendencia que ha excluido casi en su generalidad el tema de las políticas públicas de su radar. Las conclusiones a las que estos investigadores han llegado describen modelos de políticas públicas en los que hay un tratamiento desagregado de la actividad física, el deporte y la recreación, además de fortalecer sistemas de alineación con enfoques desarrollistas con prioridad en el alto rendimiento (por legitimación de sistemas de gobierno y de poder). 
La idea del registro de las políticas públicas que, en materia de actividad física, deporte y recreación, se desarrollaron en Venezuela durante el período (1999 a 2014), surge por la necesidad de documentar logros y deudas sociales de las políticas públicas en la época. Para ello es necesario contextualizar el modelo de país y de Estado que existía, y que, de alguna forma condiciona lo que sucede a posteriori. Es necesario considerar que, en Venezuela, antes de 1999, y en el marco de la llamada democracia representativa, la actividad física y el deporte, eran aspectos de la vida pública atendidos exclusivamente desde el Instituto Nacional de Deportes (IND).

Importantes logros se reconocen al IND (fundado en junio de 1949), especialmente en desarrollo de infraestructura deportiva, legislación, organización deportiva e incorporación del país en el concierto deportivo universal. Desde su creación ha sido la institución que ha liderado los esfuerzos que, en materia de actividad física y deporte se han realizado. En algún momento, el IND fue adscrito a un ministerio, tal y como ocurrió con el Ministerio de la Juventud en la primera magistratura de Carlos Andrés Pérez (1974-1979), y con el Ministerio de Familia en la presidencia de Jaime Lusinchi (1984-1989). Posteriormente fue adscrito al Ministerio de Educación, Cultura y Deportes, hasta que en 2006 se creó el Ministerio del Poder Popular para el Deporte (MPPD). Finalmente, en 2014 este ministerio se fusionó con el de Juventud pasando a denominarse Ministerio del Poder Popular para la Juventud y el Deporte (MPPJD), y con esto su adscripción a este recién creado ministerio.

Si bien es cierto que se registran logros importantes, es de considerar que, la actividad física como programa, era desarrollada a través del IND desde la premisa del episodio (en período previo al estudiado en este trabajo), esto es, los días festivos, algún que otro cierre de calle, la celebración del Día del Deporte, o el Día del Desafío, la celebración de algún festival deportivo bajo el eufemismo del programa de Deporte para 
Registro y Caracterización de las Políticas Públicas en Materia de Actividad Física, Deporte y

Todos, etc. Esto hacía que la actividad física fuese atendida sin una política definida, sin un propósito común claro, para grupos minúsculos, lo cual era aprovechado por emporios comerciales, gimnasios, clubes deportivos privados y similares. No existían planes o programas para atender de manera permanente y masiva a la población. Los logros de las políticas públicas eran medidos en términos de participación deportiva de alto rendimiento, cantidad de medallas obtenidas, desarrollo de infraestructura y el monocultivo de ciertas disciplinas deportivas. Los planes y programas realizados estaban orientados a fortalecer selectivamente al deporte de alto rendimiento. Deporte para Todos existió con anterioridad a 1999, pero era un programa sin proyecto social, cayendo en un activismo rutinario y esporádico para el cumplimiento de responsabilidades en cada una de las adscripciones administrativas y ejecutivas.

La recreación fue minusvalorada hasta antes de 2007; estando subordinada a la lógica directiva del deporte. Los riesgos del actual proceso son los mismos: rutina, activismo, subordinación al deporte. La administración de programas de recreación era potestad de instituciones como el Consejo Venezolano del Niño (creado por Eleazar López Contreras en 1936, dependiente del Ministerio de Sanidad y Asistencia Social), la Fundación del Niño (creada en 1964 como Festival del Niño, rebautizada en 2008 como Fundación Nacional “El Niño Simón”), y el Instituto de Capacitación y Recreación de los Trabajadores [INCRET (creado en 1954)]. Este último:

Es un ente adscrito al Ministerio del Poder Popular para el Proceso Social de Trabajo, que dentro del plan estratégico nacional tiene como línea de servicio la ejecución de políticas y acciones que propicien el desarrollo de la recreación, turismo y cultura socio-laboral y deporte laboral, según lo dispuesto en la Constitución Nacional de la República Bolivariana de Venezuela, la Ley Orgánica de Prevención, Condiciones y Medio Ambiente del Trabajo (LOPCYMAT), y el Plan de la Patria. Actualmente, el instituto orienta sus esfuerzos en apoyo al Plan Nacional de Recreación (sic) "Vivir Bien" donde se concibe la cultura de recreación como crítica, liberadora, incluyente, humanista y ambientalista (INCRET, 2014; sec. 1/1). 
Registro y Caracterización de las Políticas Públicas en Materia de Actividad Física, Deporte y

Recreación en Venezuela (Período 1999-2014)

Alixon Reyes

En el período señalado, esto es, 1999-2014, la recreación recibió atención, no

obstante, se hace necesario destacar un aspecto que, investigadores como Vizcaya y

Suárez (2015), mencionan desde un punto de vista crítico:

\begin{abstract}
En las precisiones teórico-conceptuales de la política deportiva del Estado, se encuentra una preeminencia del concepto de deporte sobre los de educación física y recreación. En el artículo 111 de la Constitución de la República Bolivariana de Venezuela, se menciona siete veces la palabra deporte y sus derivadas (deportistas y deportivas), dos veces, recreación y sólo una la frase educación física. En los demás documentos del Estado persiste el desequilibrio en la amplia utilización de la palabra deporte y la limitada presencia de los vocablos recreación y educación física. En definitiva, los conceptos de educación física y recreación aparecen como accesorios y complementarios; apéndices del concepto matriz: deporte. Más allá de un ejercicio académico por la precisión teórico-conceptual, interesa destacar que las limitaciones teóricas y conceptuales tienen efecto práctico en la aplicación de la política deportiva al menos en dos grandes vertientes: La confusión entre las competencias específicas y las competencias que realizan los organismos del Estado: municipales, regionales y nacionales. Estos cumplen sus funciones de manera indiferenciada, indistintamente, y sin una jerarquización adecuada; una instancia estatal invade el ámbito de competencia de otra y descuida lo que le compete específicamente. Con relación a las actividades que se realizan en la educación física y la recreación, las mismas están relacionadas directamente con la política del deporte, pero se distorsiona pues existe un mayor interés por los resultados específicos del deporte. No obstante, estos elementos negativos con relación a las políticas que sirven de base al Ministerio de Deporte se han mejorado los resultados con el triunfo del gobierno del presidente Hugo Chávez (sec. $1 / 1)$.
\end{abstract}

\title{
Metodología
}

Para registrar y caracterizar los planes y programas que, enmarcados en las líneas sociales y políticas de acción del Estado, se desarrollaron como políticas públicas entre 1999 y 2014, se emplea una metodología histórica, privilegiando la técnica documental y el análisis de contenido. Para ello se determinan los programas desarrollados por las instituciones rectoras de la actividad física, el deporte y la recreación. Se trabajó con documentación oficial de instituciones y organismos gubernamentales; se incluyen Memoria y Cuenta de los ministerios ejecutivos responsables, registros y balances de gestión, páginas web oficiales, textos emanados de asesores ministeriales, gacetas y resoluciones, leyes, además de declaraciones públicas de funcionarios del Estado. 


\section{Resultados y Discusión}

A continuación, se plantean los resultados de la investigación:

\section{Caracterización y registro de las políticas públicas}

La creación del Sistema Nacional de Deporte, Actividad Física y Educación Física (SNAFDEF), supone uno de los logros obtenidos en el período registrado (19992014). Articula la actividad física, el deporte y la Educación Física y tiene como base la masificación y democratización de la actividad física en el barrio y la escuela. El SNAFDEF engrana esta política con la política educativa, habida cuenta que la Educación Física termina siendo la base del sistema. Sus líneas de acción son:

\section{Actividad física}

La actividad física es una dimensión de atención de la política pública, y cuenta con el Viceministerio de Actividad Física y Recreación en el MPPJD. Contempla:

\section{Misión Barrio Adentro (Deportivo I)}

De acuerdo con la Comisión de Enlace para la Internacionalización de las Misiones Sociales (CEIMS) del Ministerio del Poder Popular para Relaciones Exteriores (2014) de la República Bolivariana de Venezuela, la Misión Barrio Adentro surge en abril del año 2003. No obstante, es el 31 de Julio de 2004, cuando el presidente Hugo Chávez, crea (de manera oficial) la Misión Barrio Adentro Deportivo (MBAD):

[...] con el objetivo de elevar los niveles de salud y calidad de vida de la población, así como la promoción de la práctica de ejercicios físicos, el empleo del tiempo libre, la capacitación de promotores deportivos y la recreación sana de niños, jóvenes y adultos (CEIMS, 2014).

¿Por qué se dice "de manera oficial”? Pues, porque ya se venía desarrollando en Caracas un proyecto piloto con la incorporación de profesores cubanos. De acuerdo con ECURED (2014), “Se inicia en 2002 con 16 profesores cubanos como un pequeño proyecto piloto en el municipio Libertador, impulsado por el alcalde Freddy Bernal" 
Registro y Caracterización de las Políticas Públicas en Materia de Actividad Física, Deporte y

Recreación en Venezuela (Período 1999-2014)

Alixon Reyes

(sec. 1/1). Las raíces de la MBAD están demarcadas en el proyecto que Hugo Chávez

(siendo candidato presidencial) delineara y denominara Propuesta para transformar a

Venezuela. La MBAD parte de un principio básico de democratización en todos los

órdenes de la vida pública (RAMÍREZ Y BASTARDO, 2007), y entre sus programas

están: ajedrez comunitario, círculo de abuelos, bailoterapia, cultura física (profiláctica y

terapéutica), gimnasia laboral, gimnasia para niños, preparación física para

embarazadas, etc. La Misión de la MBAD, es:

Brindar servicios de calidad con eficiencia y eficacia a la población venezolana y a entidades vinculadas al ámbito de actuación de la actividad física, el deporte y la recreación, mediante el desarrollo de proyectos asociados, que contribuyan a acelerar el proceso de inclusión social masivo que el Gobierno Bolivariano promueve en su Proyecto Nacional Simón Bolívar (MPPD, 2010; p. 71).

De igual manera, el MPPD (Ídem), informa que la Visión de la MBAD es:

Ser una expresión humanista del proceso de cambio revolucionario en materia de deporte, actividad física y recreación, que se evidencia en el mejoramiento notable de los indicadores de salud, educación y bienestar social, y en la contribución al fortalecimiento de los valores políticos, ideológicos y socio-humanistas del Gobierno Bolivariano.

Sus objetivos son:

Propiciar el uso del tiempo libre, combatir el ocio y la violencia, atacar de forma integral los factores que generan la degradación biológica, social y psicológica del ser humano, a través de un programa que busca articular ciudadanos activos, saludables y organizados para desarrollar sus talentos y capacidades físicas e intelectuales, con el propósito de afrontar la reconstrucción integral de la Patria mediante la inclusión de todas y todos los ciudadanos, utilizando el deporte, la actividad física y la recreación como herramientas integradoras y promotoras de los procesos de cambios que vive el país (Ídem).

De acuerdo con Héctor Rodríguez (ministro del deporte para 2010), el presidente Hugo Chávez, elevó en $2.000 \%$ la partida presupuestaria para el deporte desde el año 1999 cuando asumió la Jefatura del Estado hasta el año 2010 (fecha de la declaración). En ese período, el presupuesto para el deporte se incrementó de Bs. 112.853.489,20 a Bs. 6.830.614.741.00, elemento que se refleja en el aumento de atletas en Juegos 
Registro y Caracterización de las Políticas Públicas en Materia de Actividad Física, Deporte y Recreación en Venezuela (Período 1999-2014)

Alixon Reyes

Olímpicos, mayor obtención de medallas y más beneficiados por la MBAD, entre otros [AGENCIA VENEZOLANA DE NOTICIAS (AVN), 2010b]. A esto habría que sumarle el monto de Bs. 1.259.763.806,23, ejecutados durante 2011 (MPPD, 2012b). Entre masificación, alto rendimiento, atención de atletas y glorias deportivas, fueron destinados 643.450.352,00 Bs. (MORENO, 2013; CIUDAD CARACAS, 2012). Para el ejercicio fiscal 2013, el MPPD presentó una inversión por la cantidad de Bs. 4.122.051.461,94, (MPPD, 2014).

El incremento de la inversión en los dos últimos ejercicios fiscales obedece al ingreso logrado por el Fondo Nacional para el Desarrollo del Deporte, la Actividad Física y la Educación Física, que en 2013 ascendió a Bs. 1.114.034.775,76, aunado a los ingresos vía Instituto Nacional de Hipódromos (INH). El incremento en la inversión social en materia de actividad física, deporte y recreación para 2013, implica el ejercicio del derecho reivindicado por el Estado. Moreno (2013) comenta que, toda la inversión que se ha hecho oficial no contempla "lo invertido en la construcción o reparación de 1.885 infraestructuras deportivas (2.151.450.178,73 Bs., hasta 2011), lo destinado a la organización de eventos internacionales o las asignaciones especiales a atletas particulares" (sec. 1/1).

\section{Misión Barrio Adentro (Deportivo II)}

Fue creada el 12 de junio de 2005, para fortalecer los proyectos comunitarios dando continuidad a la MBAD I. Ahí se incorporan festivales deportivos comunitarios, asesorías a profesores de Educación Física en las escuelas, desarrollo de composiciones gimnásticas a nivel escolar, desarrollo de módulos deportivos construidos para el compartir y la sana competencia, deporte masivo comunitario, entre otros. De acuerdo con el MPPD (2010), el impacto generado por MBAD I y II, ha sido positivo: 
mejoramiento de las relaciones interpersonales, apoyo al trabajo de los Consejos Comunales, atención mediante la integración y apoyo a la labor de las misiones sociales, elevación de la autoestima, autonomía y socialización, influencia en la modificación de la conducta, impulsando la práctica deportiva como un mecanismo de superación. En el acto público en el que la MBAD cumplía 10 años de inaugurada, el ministro del deporte de entonces, Antonio Álvarez, decía: “Hoy en día ha atendido más de 6 millones de venezolanos y se encuentra en los 24 estados del país y en los 335 municipios con la mejora de la calidad de vida a través de la masificación del deporte, la actividad física y la recreación" (OVIEDO, 2014; sec. 1/1).

\section{Parques Biosaludables}

Los parques biosaludables se incorporaron para promover la masificación de la actividad física, el deporte y la recreación en todo el país. Se instalaron en diversos espacios públicos con equipos (para acondicionamiento y gimnasia pasiva) y máquinas estacionarias. Los lugares fueron: parques, plazas públicas, caminerías, paseos aeróbicos, boulevares, etc. El viceministro de deportes para entonces, José Alejandro Terán, informó: “existen 123 parques biosaludables instalados en los 24 estados de Venezuela, que ayudan a que las personas se integren al deporte" (NUEVA PRENSA, 2014; sec. 1/1). Igualmente indicó: "5 millones 519 mil 952 personas han sido beneficiadas gracias al convenio integral de cooperación Cuba-Venezuela, mientras 8 millones 548 mil 490 han sido dignificadas gracias a la política de masificación del deporte, actividad física y la recreación" (Ídem).

\section{Deporte}

En lo referente al deporte, los programas consideran los siguientes planes: 


\section{1- Iniciación deportiva}

La iniciación deportiva se atendió a través de escuelas de formación deportiva, escuelas de iniciación, la creación de pequeñas ligas, la Liga "Samuel Robinson", creación y consolidación de semilleros de deportes, apoyo al deporte menor, etc. Esta política se articuló con la masificación deportiva, que a su vez atiende al deporte escolar (juegos escolares en sus diferentes fases), los festivales deportivos comunitarios de la mano con MBAD y la misión cubana. Un programa en el que se articula el deporte de iniciación y el desarrollo de la Educación Física es el de los Simoncitos Deportivos.

Está dirigido a atender a niños y niñas en las edades comprendidas de 0 a 6 años, a través de actividades lúdico-afectivas con el fin de contribuir al desarrollo de sus habilidades motrices y mejorar las relaciones sociales en la participación de actividades grupales (MPPD, 2010; p. 71).

\section{Masificación deportiva}

"La masificación deportiva es un fenómeno que caracteriza el trabajo del Ministerio del Deporte en la República Bolivariana de Venezuela" (FIGUEREDO y GONZÁLEZ, 2013; sec. 1/1). Así, la política de masificación ha diversificado las disciplinas deportivas, ha creado nuevos espacios, y ha aumentado de manera progresiva la cantidad de practicantes de actividad física y/o deporte. En virtud del derecho constitucional consagrado en el artículo 111, la masificación deportiva, como política, contempla la inclusión de toda la población a la práctica regular y sistemática de la actividad física y el deporte, rompiendo con el elitismo y favoreciendo a las mayorías excluidas. El ministro Héctor Rodríguez, en su momento, comentó:

Lo más importante de estas políticas es que nosotros no formamos máquinas para la competición y la generación de medallas, sino para la masificación y la práctica del deporte en las comunidades y en los diferentes sectores de la vida nacional (AVNa, 2010; sec. 1/1). 
Alejandra Benítez, deportista y quien sucedió en el cargo a Héctor Rodríguez en el MPPD, sostuvo: “en la Revolución liderada por Chávez el medallero era importante, pero más aún la masificación del deporte para beneficio de la población" [BANCO CENTRAL DE VENEZUELA (BCV), 2014; sec. 1/1]. En segundo lugar, la masificación busca generar indicadores que eleven las condiciones psicofísicas de vida de la población; fomentar la autoregulación por parte de la población en cuanto a la cultura física y la gestión deportiva comunitaria; fomentar la participación del Poder Popular en la toma de decisiones, la generación, construcción, ejecución, evaluación y evolución de políticas públicas atingentes. El presidente Nicolás Maduro sostuvo:

\begin{abstract}
Masificar el deporte es uno de los elementos principales que vamos a colocar en el Plan de Pacificación Nacional, porque estamos empeñados en construir la paz desde adentro, la paz social en Venezuela y acabar con la fábrica de violentos, de criminales... Es una tarea primordial asumir, entre todos, la masificación del deporte, la masificación del deporte en la escuela, en los liceos, en las universidades, en las comunidades, en la calle" (AVN, 2014; sec. 1/1).
\end{abstract}

Desde el punto de vista administrativo y ejecutivo, el MPPJD, ha creado la Dirección Nacional de Masificación y Desarrollo Deportivo, desde la cual desarrolla líneas de acción y programas de atención a la población. Entre los logros están: desarrollo del poder deportivo comunal, creación de los Centros de Masificación Deportiva Integral Comunitaria, realización de festivales deportivos comunitarios, juegos nacionales comunitarios, consolidación de los Comités de Deporte y Recreación de los consejos comunales, desarrollo de infraestructura para el deporte comunitario organizado, etc., todo ello articulado con políticas dirigidas desde la MBAD y el apoyo de la misión cubana. Así, vemos la inclusión de la actividad física, el deporte y la recreación en los subsistemas: escolar, privados de libertad, trabajadores, organismos de seguridad del Estado, poblaciones indígenas, en fin, todas y todos incorporados. Elías Jaua, ministro de Comunas y Movimientos Sociales, sostuvo: 


\begin{abstract}
A partir de 1999, el Gobierno Bolivariano inició una nueva política destinada a potenciar el desarrollo deportivo... En los últimos doce años, fueron invertidos en la actividad deportiva 6.830.614.741,00 Bolívares, lo cual permitió construir o recuperar 2.885 instalaciones, edificar 3 estadios de fútbol y modernizar otros 6; crear la Universidad Iberoamericana del Deporte, 27 unidades educativas de talento deportivo y 14 centros de ciencia y medicina asociadas a esa actividad. La masificación de la práctica del deporte ya beneficia a 6.479 .713 personas que incluyen 165.000 del Poder Deportivo Comunal, 3.960.266 de la Misión Barrio Adentro Deportivo, 1.985 .000 en el deporte estudiantil, 31.803 en el Simoncito Deportivo y 337.644 del fomento de la práctica sistemática de actividades físicas, deportivas, recreativas y para la salud. La MBAD, que cubre los 24 estados del país, se convirtió en un pilar importante de la política revolucionaria hacia el deporte (JAUA, 2015; sec. 1/1).
\end{abstract}

\title{
Alto Rendimiento
}

Las líneas de acción de la política en alto rendimiento estuvieron dirigidas a la formación deportiva, la alta competencia, el ciclo olímpico, medicina y ciencias aplicadas, bienestar integral social al atleta de alto rendimiento (MPPD, 2010). La formación deportiva procura el desarrollo y fortalecimiento de la reserva deportiva nacional. Esto se logra a través de la captación y preparación de talento deportivo a través del sistema educativo, unidades educativas de talento deportivo (UETD), federaciones, asociaciones, clubes deportivos, organizaciones y movimientos sociales. Incluye captación, preparación, dotación de instituciones y materiales, topes y bases de preparación deportiva, becas, ayudas económicas y HCM, participación en competencias deportivas, etc. También supone subsidios a las federaciones y a las UETD. Hay una política formativa para personal técnico (entrenadores, metodólogos, planificadores, jueces, árbitros, dirigentes deportivos, etc.) que se apoya en convenios internacionales, en la Universidad Deportiva del Sur, el Centro Nacional de Ciencias Aplicadas al Deporte (CENACADE) y sus réplicas en los 24 estados del país.

Ahora, el programa de alta competencia incluye el Ciclo Olímpico. Para ello, el Estado garantiza recursos para apoyo, sostén y fortalecimiento de la preparación de atletas en el progreso de su perfil de rendimiento. El ciclo olímpico para Venezuela está 
compuesto de: Juegos Deportivos Bolivarianos, Juegos Deportivos Suramericanos, Juegos Centroamericanos y del Caribe, Juegos Olímpicos Juveniles, Juegos Panamericanos, Juegos Olímpicos. A esto se suman eventos y competencias específicas por disciplina deportiva: Campeonatos Mundiales, copas regionales, válidas, ligas, entre otros, con características clasificatorias para Juegos Olímpicos.

Tabla 1: Medallero y posicionamiento de Venezuela en Juegos Olímpicos de Verano 2000-2012.

\begin{tabular}{lcccccc}
\hline \multicolumn{1}{c}{ Juegos } & Atletas & Oro & Plata & Bronce & Total & Posición \\
\hline Londres 2012 & 69 & 1 & 0 & 0 & 1 & 50 \\
Beijing 2008 & 110 & 0 & 0 & 1 & 1 & 81 \\
Atenas 2004 & 48 & 0 & 0 & 2 & 2 & 68 \\
Sidney 2000 & 51 & 0 & 0 & 0 & 0 & -- \\
Totales & 278 & 1 & 0 & 3 & 4 & -- \\
\hline
\end{tabular}

Fuente: Elaboración propia.

Desde Tokio 1964 a Atlanta 1996, Venezuela llevó a 281 atletas a los juegos. Hablamos de nueve (9) ediciones olímpicas, mientras que, desde Sidney 2000 a Londres 2012 (4 ediciones), Venezuela logró llegar a 278 atletas olímpicos. De esas cuatro ediciones, en las tres últimas se han obtenido medallas olímpicas, destacando una de oro lograda por Rubén Limardo (Esgrima) en Londres 2012. Venezuela no lograba medallas olímpicas desde los Juegos en Los Ángeles 1984, cuando se obtuvieron tres medallas de bronce (con 26 atletas). De igual manera, a pesar de no tener espacios desarrollados ni estación climática para deportes de invierno, Venezuela participó en tres ediciones realizadas de los Juegos Olímpicos de Invierno. También participó en las cuatro ediciones de los Juegos Paralímpicos, logrando una medalla de oro a través de Naomi Suazo (Judo; Beijing, 2008), dos de plata y cinco de bronce.

El Comité Olímpico Internacional (COI) creó los Juegos Olímpicos de la Juventud, en los que Venezuela participó en las dos ediciones realizadas en el período, logrando una medalla de oro (María Simancas, Atletismo; Nanjing, 2014), ocho de plata y seis de bronce. En la edición de 2010 (Singapur), se asistió con 21 atletas, logrando dos medallas de plata y cuatro de bronce; mientras que en la edición de 2014 (Nanjing) 
Venezuela asistió con 59 atletas, y alcanzó una medalla de oro, seis de plata, y dos de bronce.

Al recordar los Juegos Mundiales, habría que decir que se trata de una competencia avalada por el COI, y que comprende disciplinas deportivas que no son olímpicas. Venezuela ha participado en todas las ediciones. Entre los Juegos Mundiales celebrados en Santa Clara 1981 y La Haya (1993), Venezuela había logrado tres medallas, a saber, dos de oro (Santa Clara, 1981), y una de bronce (Londres 1985). A partir de 1999 (Lahti), retomó la participación y ha logrado hasta la fecha (5 ediciones), un total de dieciocho medallas distribuidas de la siguiente manera: tres de oro, siete de plata y ocho de bronce. Seguidamente, tenemos los Juegos Panamericanos (JP). La siguiente tabla muestra el medallero final del evento en las últimas cuatro ediciones en las que Venezuela ha participado y que entran dentro del período estudiando en este trabajo.

Tabla 2: Medallero y posicionamiento de Venezuela en JP 1999-2011.

\begin{tabular}{lccccc}
\hline \multicolumn{1}{c}{ Juegos } & Oro & Plata & Bronce & Total & Posición \\
\hline Winnipeg 1999 & 7 & 16 & 17 & 40 & $8 / 27$ \\
Santo Domingo 2003 & 16 & 21 & 27 & 64 & $6 / 30$ \\
Río de Janeiro 2007 & 12 & 23 & 35 & 70 & $7 / 32$ \\
Guadalajara 2011 & 11 & 26 & 33 & 70 & $8 / 29$ \\
Totales & 46 & 86 & 112 & 244 & -- \\
\hline
\end{tabular}

Fuente: Elaboración propia.

En las últimas tres ediciones de los juegos Venezuela ha logrado superar la mayor cantidad de medallas históricas en una edición (solo por debajo de las 73 medallas obtenidas en los JP de Caracas 1983). Si bien es cierto que en Caracas 1983, Venezuela logró 73 medallas totales, 18 de ellas provinieron de la Lucha Sambo (7 de oro, 6 de plata y 5 de bronce), por detrás de los Estados Unidos (país que junto a Venezuela pujaron para que la Lucha Sambo fuese un deporte oficial para los JP de la ocasión). Rojas (2013), cuenta lo referente al Sambo de la manera siguiente: 
¿Sambo? ¿Qué rayos es el sambo? ¿Se come? ¿Se bebe? ¿Se baila? La pregunta estaba en la calle hace 30 años, porque este estilo de lucha con origen en la desaparecida Unión Soviética salió del anonimato para Venezuela en los Juegos Panamericanos de 1983 para convertirse en la principal fuente de medallas de la delegación... El sambo otorgó al país 17 (sic) de sus 73 preseas, 7 de sus 12 oros, 5 (sic) de sus 26 platas y 5 de sus 35 bronces; con lo que les echó un buen empujón a nuestros atletas, sólo superados en el medallero por las grandes potencias deportivas del continente... Oswaldo 'Papelón' Borges, presidente del Instituto Nacional de Deportes en los tiempos de los Panamericanos, cuenta cómo se incluyó la disciplina. No fue algo que estuviese en planes desde el principio, así que no sorprende que tomara por sorpresa al público venezolano, más acostumbrado a ver un partido de béisbol que a dos combatientes en el tapiz. "No podemos ganar indulgencias con escapulario ajeno. Fue obra de un comunicador social llamado Andrés Eloy Dielingen, gran periodista, quien se acercó a mi oficina y me planteó lo siguiente: -'Papelón', estamos en este momento formando la Federación Internacional de Sambo, algo nuevo. -Dame detalles.; -Mira, nosotros estamos practicando sambo. Si nosotros le damos apoyo a la federación, podemos meterlo en los Panamericanos y tendríamos muchas posibilidades de medallas; -¿Qué hay que hacer?. - Me dijo que había que hablar con varios países amigos de Venezuela para que nos apoyaran. Al tener apoyo de ocho o diez países, hablamos con la Odepa (Organización Deportiva Panamericana), eso lo llevaron a la comisión técnica, vieron que había un buen número de países y nos dijeron que sí". Borges defiende la decisión tomada en ese entonces: "Metimos el sambo y el resultado es que ganamos 17 (sic) medallas. Alguna gente trató de desmeritar este triunfo, pero si nosotros no ganábamos las medallas del sambo, de todos modos, se hubiese logrado la mejor actuación de Venezuela en los Panamericanos para ese momento. Ahora, ¿que fue una habilidad de nosotros? Sí. Sí lo fue" (sec. $1 / 1)$.

La participación venezolana en los Juegos Suramericanos (JS) ha sido importante también en el período en estudio (1999-2014). Veamos a continuación:

Tabla 3: Medallero y posicionamiento de Venezuela en JS 2002-2014.

\begin{tabular}{lccccc}
\hline \multicolumn{1}{c}{ Juegos } & Oro & Plata & Bronce & Total & Posición \\
\hline Brasil 2002 & 97 & 70 & 64 & 231 & $2 / 14$ \\
Buenos Aires 2006 & 96 & 85 & 97 & 278 & $4 / 15$ \\
Medellín 2010 & 89 & 80 & 96 & 265 & $3 / 15$ \\
Santiago 2014 & 47 & 40 & 63 & 150 & $3 / 14$ \\
Totales & 329 & 275 & 320 & 924 & -- \\
\hline
\end{tabular}

Fuente: Elaboración propia.

Las dos mejores cosechas en el medallero suramericano entre 1999 y 2014

fueron en 2006 y 2010, con un preocupante descenso en 2014 (a pesar de que se logró retener el tercer lugar del medallero general). El Estado promovió y fortaleció el deporte de alta competencia, no solo en la representación de las competencias ya mencionadas, sino también en otras como los Juegos Bolivarianos, los Juegos Centroamericanos y del Caribe, Juegos Escolares Suramericanos, etc.; organizó los Juegos Deportivos Juveniles 
Registro y Caracterización de las Políticas Públicas en Materia de Actividad Física, Deporte y Recreación en Venezuela (Período 1999-2014)

Alixon Reyes

Nacionales en sus diferentes ediciones, construyó obras e infraestructura de gran envergadura como los estadios de fútbol para la Copa América Venezuela 2007, el Complejo Deportivo de Playa "Hugo Rafael Chávez Frías" en el estado Vargas (ahora 'La Guaira'); organizó eventos de magnitud como el Campeonato Mundial de Softbol Femenino, el Premundial de Baloncesto, la Copa América 2007. La Procuraduría General de la República (2014), en su página web, sostiene:

En ese momento, el presidente de la República Bolivariana de Venezuela, Hugo Chávez, le otorgó a la organización del evento categoría de asunto de Estado. El gobierno venezolano invirtió cerca de 900 millones de dólares para el desarrollo de las nuevas infraestructuras deportivas: incluyendo estadios, vialidad, mejoras a los aeropuertos y proyectos hoteleros (sec. 1/1).

El presidente Chávez dictó y firmó el decreto № 4.742 (GACETA OFICIAL Nº 38.052 de Fecha 17 de agosto de 2006), creando la Comisión Presidencial Interministerial Copa América Venezuela 2007 integrada por 13 ministerios: Educación y Deportes, Turismo, Infraestructura, Defensa, Comunicación e Información, Industrial Ligeras y Comercio, Ambiente, Trabajo y Seguridad Social, Energía y Petróleo, Industrias Básicas y Minería, Relaciones Exteriores, Interior y Justicia, Finanzas. Después de los Juegos Panamericanos Caracas 1983, la Copa América fue el evento deportivo de mayor envergadura que ha organizado al país, despertando reconocimientos de las autoridades de FIFA y Conmebol, además de registrar los mejores resultados en audiencia, ganancias, asistencia y cobertura en la historia del evento. Mingus (2012), agrega:

Las políticas públicas que el gobierno bolivariano ha desarrollado han tenido un mérito objetivo e incuestionable. No se puede acusar al Gobierno de falsificar los resultados o haber comprado una encuesta... En los juegos centroamericanos y del Caribe, desde 1938 hasta 1998 - 14 edicionesVenezuela estuvo representada con 3.362 atletas. Durante el mandato de Hugo Chávez, en sólo tres ediciones, ya han participado 1.502 deportistas. En los Juegos Olímpicos, en sólo nueve años de gobierno bolivariano — hasta los juegos olímpicos de Beijing en 2008-, participaron más atletas que en 22 años de gobierno de la IV República. Con la participación masiva de los atletas venezolanos en los Juegos Olímpicos de Londres 2012, la brecha se ampliará aún más... Eso sí es un indicador de una verdadera política de 
masificación y de integración al sistema deportivo. Estos éxitos se deben a la constante preocupación del gobierno nacional por esta área del desarrollo humano. Por una parte, con el aporte financiero y, por otra, con una nueva visión del deporte en la sociedad (p. 181-182).

\title{
Agencia Bolivariana Antidopaje
}

La Agencia Bolivariana Antidopaje (ABA) fue creada en el año 2004 por orden del presidente Hugo Chávez. A través de un Decreto Presidencial (2004), nace la ABA y es adscrita al IND. Dicho decreto, en su artículo 1, sostiene:

\begin{abstract}
Dicha Agencia tendrá como objeto la educación, prevención, control y lucha contra la práctica del dopaje en el deporte venezolano. La misma, dictará su propio reglamento interno, estructurará su propia organización y además tendrá facultades para convocar a otras Instituciones y/o especialistas, si fuera necesario.
\end{abstract}

Posterior a ello, en el año 2008, se crea también por Decreto Presidencial N ${ }^{\circ}$ 6.637 la Comisión Antidopaje de la República Bolivariana de Venezuela.

\section{Fundaexar}

Fundación para la atención integral de los atletas y exatletas jóvenes y adultos mayores. Fue creada por Decreto Presidencial N 4.741, de Gaceta $N^{\circ} 38.502$, el día 17 de agosto de 2006 (el mismo día de la conformación de la Comisión Presidencial Interministerial Copa América Venezuela 2007). Es de destacar que la fundación tenía 3 años en funcionamiento estando adscrita al IND. Posteriormente, en el año 2009, pasó a estar adscrita al MPPD en honor al Decreto Presidencial $N^{\circ} 6.670$, bajo Gaceta $\mathrm{N}^{\circ}$ 39.164. Esta fundación se suma al programa de las Glorias Deportivas.

\section{Recreación}

Históricamente la recreación fue campo minusvalorado para el sector público en Venezuela hasta el año 2007 en la segunda presidencia de Hugo Chávez. En 2007 se 
inicia un plan piloto que da pie en 2009 a una política que atiende la recreación del venezolano de manera estructural. Surgió la necesidad de un plan nacional que pensase la necesidad del ciudadano y las posibilidades que el Estado podía generar. Así nació finalmente en 2009 el Plan Nacional de Recreación para el Vivir Bien (PNRVB).

\section{PNRVB}

En la Constitución de la República de Venezuela (1961), no existía articulado alguno que otorgara a la población el derecho a la recreación. Luego, en la Constitución de la República Bolivariana de Venezuela aprobada por el pueblo venezolano en el referéndum celebrado en diciembre del año 1999, la recreación quedó expresada y consagrada como un derecho constitucional:

Todas las personas tienen derecho al deporte y a la recreación como actividades que benefician la calidad de vida individual y colectiva. El Estado asumirá el deporte y la recreación como política de educación y salud pública y garantizará los recursos para su promoción... (Artículo 111).

Hasta la puesta en marcha del PNRVB en 2009, no había existido en el país, alguna política pública específica enmarcada en la atención de la población venezolana en general desde el contexto de la recreación. Existía una corta serie de actividades esporádicas destinadas a ofrecer momentos para el esparcimiento muy específicos (a poblaciones muy específicas). Lo que sí existía era una desarticulación entre las instituciones del Estado y el sector privado que desarrollaban programas aislados en virtud de la atención a poblaciones focales en materia de recreación (REYES, 2011). Por ejemplo: planes vacacionales para los hijos e hijas de sus trabajadores(as), planes turísticos para los trabajadores(as), visitas guiadas, instalaciones deportivas (generalmente multicanchas), y planes recreacionales para quienes pudiesen costearlos. Algunas instituciones ejecutaban programas deportivos y recreativos para comunidades enmarcadas en sus rangos de acción. No obstante, un grueso de la población venezolana 
Registro y Caracterización de las Políticas Públicas en Materia de Actividad Física, Deporte y Recreación en Venezuela (Período 1999-2014)

Alixon Reyes

se quedó en estado de desatención permanente (a no ser por actividades tipo “escaramuza" o "relámpago" en tiempos de propaganda electoral). Lo que había sido planeado como posibilidad recreativa se resalta en espacios como parques naturales, plazas, canchas deportivas, etc.

El PNRVB que inicia en 2009, se venía pensando y gestando desde la iniciativa del Ejecutivo nacional, y finalmente generó una idea diferente de atención desde el contexto de la recreación en tanto se logra la satisfacción de un derecho históricamente invisibilizado, como lo es el derecho a la recreación; se ponen en marcha varios procesos que democratizan los programas recreativos, favoreciendo a las grandes mayorías y a las poblaciones más desfavorecidas; se incorpora y se da acceso a los más vulnerables a los programas del Estado en materia de recreación desde la gratuidad; se logra la articulación política, administrativa y ejecutiva de varios ministerios responsables conjuntamente con otras instituciones del Estado; se logra la articulación y la activación del Poder Popular en conjunto con el Ejecutivo Nacional para el logro del cometido; y se logra, además, la movilización y participación de movimientos sociales organizados como recreadores, preventores sociales, movimientos ecológicos, consejos comunales, madres del barrio, entre otros. En PNRVB se inició con tres momentos importantes, a saber: Festival de Ríos y Playas, Plan Vacacional Comunitario, y Reto Juvenil. Y, de hecho, uno de los programas más emblemáticos del PNRVB, es el Plan Vacacional Comunitario, que permite la inclusión de niños y jóvenes en un programa totalmente gratuito en todo el país, atendiéndoles sin ningún distingo. Desde el año 2009, año en el que inicia el Plan Vacacional Comunitario, fueron atendidos hasta 2014: 4.521.883 niños, niñas y adolescentes (ÚLTIMAS NOTICIAS, 16-07-2014).

Para 2012, según Yadira Córdoba, vicepresidenta del Área Social (en entonces), participaron 2.198.742 personas en el Festival de Playas y Ríos en el país 
Registro y Caracterización de las Políticas Públicas en Materia de Actividad Física, Deporte y Recreación en Venezuela (Período 1999-2014)

Alixon Reyes

(TORREALBA Y ROJAS, 2013), y los Juegos Deportivos Comunitarios atendieron a 2.500.000 personas a nivel nacional (ALTUVE, 2012, citando información reseñada por la AVN). El PNRVB se fortaleció con la incorporación de procesos como el Plan Nacional de Turismo, Barrio Adentro Deportivo, Plan Nacional de Actividad Física, Plan Nacional de Campismo, y otras actividades como las Caimaneras Juveniles Comunitarias, Reto Juvenil Adolescente, Plan de Turismo Estudiantil, Campismo de la Juventud Bicentenaria, Parques Biosaludables, además de temas como la movilización comunitaria, la formación popular y específica, la articulación interministerial, etc.

Desde 2009 se dan experiencias en recreación y turismo con programas ofrecidos por Venetur y el Instituto Nacional de Turismo (INT), el INCRET, la Misión Cultura, MBAD, Idenna, Inparques, los festivales comunitarios y populares artísticos, el rescate de espacios públicos, la reparación y adecuación de iglesias y catedrales, de los museos, el Plan Vacacional Comunitario en el marco del PNRVB, el fortalecimiento del Programa de Deporte Para Todos del IND, el Plan Nacional de Actividad Física, Deporte y Educación Física, la Masificación Deportiva del MPPJD, etc. Estas actividades y programas están dirigidas hacia poblaciones focales específicas y el saldo ha sido suficiente como para augurar nuevas posibilidades y retos para próximos ciclos.

Misión del PNRVB

Ser la política pública de atención social masiva, que desde la recreación, desarrolle una cultura formativa de la integración, la tolerancia, la paz, el equilibrio, el respeto el amor, la alegría, la convivencia para la práctica y el ejercicio de la libertad plena en el tiempo y la suprema felicidad social, reuniendo para ello esfuerzos de todos los sectores de la vida nacional con la participación democrática, protagónica y decisiva del poder popular y los demás poderes nacionales integrados, garantizando la equidad en todas sus formas y sentidos, creando escenarios para lograr la formación del hombre nuevo con visión nacionalista y latinoamericana (MINISTERIO DEL PODER POPULAR PARA LAS COMUNAS Y PROTECCIÓN SOCIAL, 2012).

Visión del PNRVB 
Convertirse en una plataforma pública con valores éticos, morales, sociales, recreativos, ambientales y políticos, que cree los escenarios formativos e informativos, y garantice el desarrollo permanente e integral de la población venezolana en pleno, con credibilidad y beligerancia en la puesta en práctica de políticas y estrategias que permitan atender las necesidades de las y los ciudadanos, creando conciencia preventiva, democrática, participativa, protagónica, pluralista, integradora y de impacto social que permee las políticas públicas en todo el territorio nacional (Ídem).

Los ejes del PNRVB fueron: Cultura, Prevención, Vivir Bien y Salud, Formación, Investigación, Gestión, Práctica Política, Articulación con Grandes

\author{
Misiones.
}

Objetivos del PNRVB

\title{
Objetivo general
}

Generar condiciones para la gestación de una cultura de la recreación amparada en la práctica y el ejercicio de la libertad plena en el tiempo y la apropiación de la suprema felicidad social en familia y en comunidad para el Vivir Bien (REYES, 2015).

\section{Objetivos específicos}

1. Ejecutar una política pública de atención y prevención social desde la recreación para toda la población venezolana de manera permanente en consonancia con la premisa de la suprema felicidad social y el Vivir Bien.

2. Reivindicar la recreación como derecho social para la satisfacción de las necesidades de recreación de la población venezolana y el Vivir Bien.

3. Develar la importancia de la recreación en el desarrollo de acciones preventivas, de salud, esparcimiento, descanso, educación y desarrollo, que contribuyan a la consolidación de una vida sana e integral de los y las ciudadanas.

4. Sentar las bases para la gestación y el desarrollo progresivo y permanente de una cultura nacional crítica y formativa, defensora de valores y principios éticos nacionalistas e integracionistas para el fortalecimiento de la espiritualidad de la población, la práctica y el ejercicio de la libertad plena en el tiempo.

5. Lograr la participación inclusiva y protagónica de toda la población y de todos los sectores de la vida nacional, en los procesos y programas recreativos, sociales y turísticos emanados del PNRVB.

6. Desarrollar una conciencia social y ecológica sensible a la realidad nacional que promueva la participación protagónica y decisiva del poder popular en el diseño de acciones coherentes a fin de lograr las premisas de la suprema felicidad social y el Vivir Bien.

7. Incorporar todas las expresiones lúdicas posibles en los espacios comunitarios en reconocimiento de la diversidad cultural existente en la República Bolivariana de Venezuela y los demás países de América Latina desde la libre expresión y la creación del poder popular en todos los ámbitos. 8. Desarrollar planes y programas que en conjunto con los colectivos sociales permitan la reparación, uso equilibrado y mantenimiento de espacios públicos para la recreación.

9. Desarrollar amplios programas de formación específica y formación popular en materia de recreación.

10. Desarrollar el campo de la recreación como campo profesional, ocupacional, y como plataforma para el desarrollo comunitario (Ídem). 


\section{¿Quiénes planifican en el PNRVB?}

Desde 2009 hasta 2014, el PNRVB venía siendo pensado por la Mesa Nacional del Vivir Bien (equipo nacional interministerial que reúne a todos los ministerios de la Vicepresidencia del Área Social, equipos estadales del Vivir Bien, Petróleos de Venezuela, entre otros), representantes del Poder Popular, recreadoras(es), asesores nacionales, etc. Ahora, de acuerdo con la Ley Orgánica de Recreación [LOR (2015)], el Consejo Nacional de Recreación, adscrito a la Vicepresidencia de la República, es quien se encargará de construir el Plan Nacional de Recreación (PNR) en lo sucesivo. Está conformado por representantes del sector público, del sector privado y el comunitario. Interesante es que el Poder Popular participe en todas las fases del PNR, y que la recreación se ha posicionado en el contexto jurídico durante el transcurrir de los años. Primero en la Constitución de la República Bolivariana de Venezuela (CRBV), luego en otras leyes como la Ley Orgánica de Educación (LOE); la Ley Orgánica de Protección de los Niños, Niñas y Adolescentes (LOPNA); la Ley Orgánica de Prevención, Condiciones y Medio Ambiente de Trabajo (LOPCYMAT), la Ley del Plan de la Patria 2013-2019, la LOR, la Ley Orgánica de Régimen Municipal (LORM), la Ley Orgánica del Trabajo, los Trabajadores y las Trabajadoras (LOTTT), además de los contratos colectivos de distintos gremios en todo el país.

\section{Ley Orgánica de Recreación}

La LOR fue aprobada en diciembre de 2015 por la Asamblea Nacional entrando en vigencia desde entonces. Los elementos más resaltantes son: proclamación de la recreación como derecho público, un modelo de recreación denominado como recreación liberadora, creación del Consejo Nacional de Recreación. Además, se ha de 
crear el Sistema Nacional de Recreación, y se asume la recreación como política inclusiva de educación y salud pública.

Saldo Organizativo a Nivel Sociopolítico en las Políticas Púbicas Desarrolladas en Actividad Física, Deporte y Recreación

Toda acción dirigida al accionar de la política pública debe generar un saldo organizativo, esto es, no puede quedarse exclusivamente en el programa específico, sino que, debe traspasarlo y superarlo de manera que pueda regularse a sí mismo en lo sucesivo. Es así como los esfuerzos del Estado están orientados por tres elementos: la garantía del derecho de la ciudadanía, la formación popular y la organización del poder popular. Entre los resultados más resaltantes a nivel de saldo, tenemos:

\section{Movimientos sociales y organización popular}

La organización popular lograda ha sido clave para el sostén de las políticas públicas en actividad física, deporte y recreación en Venezuela entre 1999 y 2014. Esto implica la gestación y consolidación en el tiempo de movimientos sociales y de colectivos en todo el país. Los más reconocidos a la fecha son: movimiento nacional de recreadores, movimiento venezolano de actividad física, movimiento de cultores y cultoras, etc. Son movimientos que tienen agenda propia, independiente de los estamentos gubernamentales, y han trabajado de forma consecuente y dinámica participando en la construcción, gestión y ejecución de las políticas. Han ejercido una contraloría popular y presentado propuestas de gestión, formación y movilización.

\section{Convenio Integral de Cooperación Cuba-Venezuela (y otros convenios)}


Registro y Caracterización de las Políticas Públicas en Materia de Actividad Física, Deporte y

Recreación en Venezuela (Período 1999-2014)

Alixon Reyes

Convenio firmado el 30 de octubre del año 2000 entre Venezuela y Cuba, abarca varias áreas de cooperación, siendo el deporte una de ellas. La cooperación implica trabajo conjunto en tres áreas, a saber: Asistencia Técnica: presencia de entrenadores cubanos para alto rendimiento, para la atención de la MBAD, y especialistas en ciencias aplicadas para el desarrollo del CENACADE a nivel nacional; Bases y topes de entrenamiento: asesoramiento técnico de selecciones nacionales, realización de análisis antidoping en laboratorio cubano, bases y topes de entrenamiento en Cuba e intercambios deportivos en el marco de la Alianza Bolivariana de las Américas (suscrito en trabajo conjunto de la IX Comisión Mixta Cuba-Venezuela); Formación académica del talento humano: formación de talento humano en Cuba a nivel de pregrado y postgrado, participación en eventos científico-académicos en el ámbito del deporte, ciencias aplicadas y Educación Física.

Además del Convenio Cuba-Venezuela, nuestro país ha suscrito convenios con otros países en materia de actividad física, deporte y recreación. Según Altuve (2008) y según información suministrada por servicios informativos del MPPJD y la Asamblea Nacional, entre estos convenios están:

Tabla 4: Países y convenios. Fuente: Elaboración propia.

\begin{tabular}{|c|c|}
\hline País & Convenio \\
\hline Rusia & $\begin{array}{l}\text { Calendario de Cooperación Deportivo, apoyo en disciplinas de alto rendimiento, ciencia } \\
\text { y medicina del deporte, masificación deportiva, tecnología deportiva, infraestructura, } \\
\text { laboratorio antidoping, programas para el deporte femenino y administración del } \\
\text { deporte. Además de ello se incluye: trabajo mutuo a nivel informativo, formación, } \\
\text { intercambios deportivos, intercambio de entrenadores y personal técnico. }\end{array}$ \\
\hline Colombia & Programa de intercambio educativo, cultural y deportivo 2004-2006. \\
\hline $\begin{array}{l}\text { Corea del } \\
\text { Norte }\end{array}$ & Modelo de Memorando de Entendimiento. \\
\hline $\begin{array}{l}\text { Países del } \\
\text { Caribe }\end{array}$ & $\begin{array}{l}\text { Mecanismo de cooperación deportiva a partir de la MBAD y ligas caribeñas para aportar } \\
\text { atención a las comunidades a través de intercambios deportivos, técnicos especializados } \\
\text { y de talleres. Se elaboró, además, el documento rector de la Universidad Iberoamericana } \\
\text { y caribeña del Deporte, que se concretó en la creación de la Universidad Iberoamericana } \\
\text { del Deporte, renombrada como Universidad Deportiva del Sur. }\end{array}$ \\
\hline Mali & Infraestructura \\
\hline China & $\begin{array}{l}\text { Desarrollo de un Centro de Alto Rendimiento, construcción de parques biosaludables, } \\
\text { acuerdo con la Universidad del Deporte de Beijing, topes de preparación de atletas, } \\
\text { asistencia permanente a las Esperanzas Olímpicas, acercamiento a la Oficina de } \\
\text { Administración del Deporte de la República Popular China. }\end{array}$ \\
\hline Japón & Intercambio entre las universidades formadoras de profesionales en el campo del \\
\hline
\end{tabular}




\begin{tabular}{|c|c|}
\hline & $\begin{array}{l}\text { deporte, la actividad física. Por Venezuela, la Universidad Deportiva del Sur y por } \\
\text { Japón, a Universidad de Ciencias Deportivas. }\end{array}$ \\
\hline MERCOS & Acuerdo de entendimiento entre la comunidad del MERCOSUR en materia deportiva e \\
\hline & intercambio de experiencias en organización popular, masificación deportiva, etc. \\
\hline Argentina & $\begin{array}{l}\text { Acuerdo de cooperación en materia deportiva; Convenio de cooperación deportiva entre } \\
\text { el IND y la Secretaria de Turismo y Deporte de Buenos Aires. }\end{array}$ \\
\hline Portugal & $\begin{array}{l}\text { Memorándum de entendimiento en áreas de cooperación institucional, alto rendimiento, } \\
\text { ciencia y tecnología aplicadas al deporte, medicina del deporte, lucha contra el dopaje, } \\
\text { patrocinio y mecenazgo deportivos, organización de eventos deportivos, formación de } \\
\text { especialistas deportivos y gestores, protección del joven atleta, mujer y deporte, etc. }\end{array}$ \\
\hline Brasil & Acuerdo de cooperación en materia deportiva. \\
\hline República & Acuerdo de cooperación en materia deportiva, consistente en intercambio para \\
\hline Árabe Siria & $\begin{array}{l}\text { formación deportiva, intercambios entre profesionales y técnicos deportivos, } \\
\text { entrenamientos conjuntos entre seleccionados de ambos países, investigación conjunta } \\
\text { en ciencias aplicadas al deporte. }\end{array}$ \\
\hline Bolivia & $\begin{array}{l}\text { Acuerdo para la aplicación de la Alternativa Bolivariana para los pueblos de Nuestra } \\
\text { América y el Tratado de Comercio de los Pueblos (Entre Venezuela, Cuba y Bolivia). En } \\
\text { este tratado Cuba y Venezuela se comprometen a ofrecer su colaboración en el } \\
\text { desarrollo del deporte, incluyendo las facilidades para la organización de competencias y } \\
\text { bases deportivas en ambos países. Venezuela formará cuadros dirigenciales deportivos, } \\
\text { ayudará en cuanto a masificación deportiva, ciencias aplicadas al deporte, formación } \\
\text { técnica de entrenadores. }\end{array}$ \\
\hline Bulgaria & $\begin{array}{l}\text { El Instituto Nacional del Deporte (IND) y la Agencia Estatal de la Juventud y el Deporte } \\
\text { de Bulgaria han firmado un convenio para intercambio de selecciones nacionales, topes } \\
\text { de preparación, uso del Centro de Alto Rendimiento de Bulgaria, formación académica } \\
\text { bilateral. }\end{array}$ \\
\hline Chile & Convenio de cooperación en materia deportiva. \\
\hline Ecuador & Acuerdo de cooperación en materia deportiva. \\
\hline
\end{tabular}

Fuente: Elaboración propia.

\section{Creación de la Universidad Iberoamericana del Deporte}

En 2006 fue creada la Universidad Iberoamericana del Deporte en San Carlos, estado Cojedes. Su primer rector fue Ángel Flores. De acuerdo con el portal web, esta universidad, en su misión:

[...] se compromete con un proyecto educativo, cultural y social que implica la divulgación, generación y sistematización del conocimiento y la apertura a experiencias inéditas en los ámbitos de formación, investigación y proyección social en los niveles de pregrado y postgrado en los campos científicos, tecnológicos, sociales y humanísticos asociados a la actividad física, el deporte y sus áreas afines para lograr la vinculación permanente del desarrollo socioeconómico, ambiental, educativo y deportivo local, regional y nacional y a su vez promover la integración con los Pueblos del Sur (2015, sec. $1 / 1)$.

Su visión la lleva a plantearse:

Ser una Institución de Educación Superior líder en la formación humanista, integral, permanente y de calidad del talento humano con vocación hacia la Actividad Física, el Deporte y sus áreas afines en el ámbito nacional y los pueblos del sur en el ámbito internacional, asumiendo el compromiso del Estado, lo público y lo social en correspondencia con la aplicación de las TIC 
s para el desarrollo de sus planes, programas y proyectos, la municipalización y el resto de sus procesos fortaleciendo su incidencia efectiva sobre las prácticas que determinan el estilo de vida y la salud de los pueblos (Ídem).

La universidad ofrece las siguientes carreras: Gestión Tecnológica del Deporte, Entrenamiento Deportivo, Actividad Física y Salud. El plan de formación de la universidad tiene correspondencia con el Plan Estratégico Nacional de Formación Permanente que desarrolla el IND. La universidad pasó a denominarse (desde 2010) Universidad Deportiva del Sur (UDESUR), y para 2014 tenía estudiantes de varias nacionalidades, a saber: Angola (9), Bolivia (28), Colombia (1), Ecuador (5), El Salvador (3), Haití (19), Mozambique (11), Paraguay (1), y Venezuela (1056). Al año 2014, la UDESUR había graduado 960 profesionales (CIUDAD CARACAS, 2014).

\section{Creación del Ministerio del Poder Popular para el Deporte}

De acuerdo con la Memoria y Cuenta del MPPD, este ente se creó mediante Decreto $\mathrm{N}^{\circ}$ 5.022, de fecha 27 de noviembre de 2006 (Gaceta Oficial $\mathrm{N}^{\mathrm{o}}$ 38.574, 29 de noviembre de 2006). Se denominó Ministerio del Poder Popular para el Deporte, según Decreto $\mathrm{N}^{\circ} 5.103$ de fecha 28 de diciembre de 2006 (Gaceta Oficial Extraordinaria $\mathrm{N}^{\mathrm{o}}$ 5.836, 8 de enero de 2007). Además, por Decreto Presidencial № 1213 (Gaceta Oficial $\mathrm{N}^{\circ}$ 40.488), se anunció la fusión de dos ministerios creándose el Ministerio del Poder Popular para la Juventud y el Deporte (MPPJD), con fecha 02 de septiembre de 2014. De acuerdo con el portal web del MPPJD (2015):

El Ministerio del Poder Popular para el Deporte (MPPPD) fue creado 27 de noviembre de 2006 por el presidente de la República Bolivariana de Venezuela, Hugo Rafael Chávez Frías, con la finalidad de definir, implantar, regular y supervisar las políticas, la planificación y realización de las actividades del Ejecutivo Nacional en materia deportiva. Su fundación nace a partir del Instituto Nacional de Deportes, ente descentralizado que se fundara el 22 de junio de 1949 durante la presidencia de Carlos Delgado Chalbaud, y que estaba hasta entonces adscrito Ministerio de Educación, Cultura y Deportes. La primera persona en ocupar la cartera ministerial del deporte fue el Prof. Eduardo Álvarez (2006-2007), posteriormente ocuparon el cargo, Lic. Victoria Mata (2008-2010), abogado Héctor Rodríguez (2010-2013), la esgrimista Alejandra Benítez (2013) y en la actualidad se desempeña al frente del MPPPD el beisbolista Antonio Álvarez (sec. 1/1). 
Misión

Contribuir a la formación integral de las ciudadanas y ciudadanos, a través de la ejecución de políticas tendentes a masificar, promover e inculcar en la población, la práctica sistemática y sostenida de la actividad física para la salud, el deporte y la recreación (Ídem).

Visión

\begin{abstract}
Garantizar el derecho social de la población venezolana a la práctica sistemática de la actividad física, el deporte y la recreación, mediante una gestión de calidad, a tono con las tendencias mundiales del sector y los principios éticos de solidaridad, inclusión social, equidad, participación y corresponsabilidad, del socialismo del siglo XXI (Ídem).
\end{abstract}

\title{
Ley Orgánica de Deporte, Actividad Física y Educación Física
}

La Ley Orgánica de Deporte, Actividad Física y Educación Física (LODAFEF), finamente fue aprobada en sesión de la Asamblea Nacional (Gaceta Oficial № 39.741, 23 de agosto de 2011) iniciando así "un proceso de transformación en la promoción, organización y administración del deporte y la actividad física como servicios públicos, reconociéndolos como derecho fundamental de los ciudadanos y ciudadanas, y como un deber social del Estado" (MPPD, 2012a; p. 04). Entre algunos de los puntos positivos de esta ley están: creación del Sistema Nacional del Deporte, la Actividad Física y la Educación Física; y ello en tanto se articula la Educación Física con la actividad física y el deporte. Además de ello, la inclusión social y la priorización de la Educación Física junto a la actividad física y el deporte son claves para comprender la magnitud y el espíritu de la ley en razón de un tejido de políticas públicas. El artículo 12 de la LODAFEF así lo recoge:

Se declara como prioridad de la política deportiva nacional, la masificación de las buenas prácticas del deporte, la actividad física y la educación física y se incorporan como elementos transversales de las políticas Estatales en materia de vivienda y hábitat, pueblos indígenas, trabajo, mujer e igualdad y equidad de género, juventud, educación, salud, seguridad, defensa, comunicación, organización popular, entre otras.

Se crean el CENACADE, el Fondo Nacional para el Desarrollo del Deporte, la Actividad Física y la Educación Física (permite el financiamiento de proyectos 
deportivos, en actividad física, para Educación Física, en ciencias aplicadas y recreación), el Registro Nacional del Deporte, la Actividad Física y la Educación Física, etc. Finalmente, establece como derecho la creación de colectivos de deporte, actividad física y Educación Física en los espacios comunitarios, representando una novedad y la articulación del Poder Popular en el ejercicio de la gestión pública.

\section{Fondo Nacional para el Desarrollo del Deporte, la Actividad Física y la Educación} Física

El Fondo Nacional para el Desarrollo del Deporte, la Actividad Física y la Educación Física, creado a partir de la LODAFEF (2011), ofrece posibilidades financieras para el desarrollo de una cultura física. Se trata de un fondo en el que los contribuyentes son aquellas personas naturales o jurídicas, empresas u organizaciones privadas y públicas que realicen actividades económicas de lucro cuya utilidad neta supere las 20.000 Unidades Tributarias. Para ello deben darse de alta en el Registro Nacional del Deporte, la Actividad Física y la Educación Física, e iniciar su proceso de aporte al fisco. También se pueden hacer donaciones vía fondo. De acuerdo con el MPPD (2013), los fondos recaudados se destinan a: fortalecimiento de políticas y proyectos de masificación deportiva, actividad física y Educación Física; desarrollo del deporte de alto rendimiento; seguridad y atención de las y los atletas (activos, en retiro, glorias deportivas); proyectos de investigación científica en el campo del deporte, la actividad física y la Educación Física en universidades de gestión pública; patrocinio del deporte profesional; producción de bienes asociados al deporte; promoción de empresas de propiedad social directa, etc.

\section{Creación del CENACADE}


El CENACADE nace en 2004 por iniciativa del presidente Hugo Chávez. El proyecto se expande en 2008 a los 24 estados del país, asunto que se logra durante el período transcurrido hasta 2014. El MPPD (2010) sostiene:

\begin{abstract}
Son organizaciones en las que se coordina, ejecuta y evalúa el control biomédico del entrenamiento deportivo de las y los atletas de las Selecciones Nacionales y Regionales, así como de la población que realiza actividad física, a través de la medicina del deporte y sus ciencias aplicadas, con la finalidad de optimizar el rendimiento deportivo. En ellos se realizan, asimismo, actividades de docencia e investigación que redundan en la mejora de la atención médica a los atletas (p. 46).
\end{abstract}

Dentro de los objetivos del CENACADE están: asistencia integral a los atletas, deportistas y practicantes; control médico del entrenamiento; formación de talento humano; asesoría al colectivo técnico de las distintas selecciones deportivas; pautas de acompañamiento a las comunidades en la práctica de actividad física a fin de mejorar la calidad de vida; articulación de políticas y establecimiento de convenios con universidades del país para impulsar el desarrollo de las ciencias aplicadas al deporte. Las especialidades de atención son: medicina deportiva, cardiología, traumatología, ginecología, odontología, fisioterapia, antropometría, laboratorio, mesoterapia, Láserterapia, hidromasaje, ultrasonoterapia, fisiología del esfuerzo, biomecánica, etc.

\title{
Plan Nacional de Actividad Física, Deporte y Educación Física 2013-2025
}

Basado en el artículo 111 de la Constitución de la República Bolivariana de Venezuela, y después de varias consultas, el MPPD lanzó el Plan Nacional de Deporte, Actividad Física y Educación Física 2013-2025. Este plan responde al Proyecto Nacional Simón Bolívar y al Plan Socialista del Desarrollo Económico y Social de la Nación. Los principios rectores son: a) Inclusión social en el deporte, la actividad física y la Educación Física; b) Deporte, actividad física y Educación Física como medios para mejorar la calidad de vida y la salud; c) Participación del Poder Popular como base de la gestión pública deportiva; d) Deporte competitivo en todos los ámbitos del sistema. 
Registro y Caracterización de las Políticas Públicas en Materia de Actividad Física, Deporte y

Recreación en Venezuela (Período 1999-2014)

Alixon Reyes

\section{Ley para el Plan de la Patria 2013-2019}

Promulgada en Gaceta Oficial N 6118, la Ley para el Plan de la Patria 2013-

2019 se comporta, además, como el Segundo Plan Socialista de Desarrollo Económico

y Social de la Nación para el período 2013-2019. Este plan (convertido en ley de

Estado), recoge los cinco grandes objetivos históricos de la nación, a saber:

1). Defender, expandir y consolidar el bien más preciado que hemos reconquistado después de 200 años: la Independencia Nacional; 2). Continuar construyendo el socialismo bolivariano del siglo XXI, en Venezuela, como alternativa al sistema destructivo y salvaje del capitalismo y con ello asegurar la "mayor suma de seguridad social, mayor suma de estabilidad política y la mayor suma de felicidad" para nuestro pueblo; 3). Convertir a Venezuela en un país potencia en lo social, lo económico y lo político dentro de la Gran Potencia Naciente de América Latina y el Caribe, que garanticen la conformación de una zona de paz en Nuestra América; 4). Contribuir al desarrollo de una nueva Geopolítica Internacional en la cual tome cuerpo un mundo multicéntrico y pluripolar que permita lograr el equilibrio del Universo y garantizar la Paz planetaria; 5). Preservar la vida en el planeta y salvar a la especie humana (Ídem).

Estos cinco objetivos históricos presentan la perspectiva política, cultural, social, económica y estratégica de Venezuela. Desde el contexto de la actividad física, el deporte, la recreación y la Educación Física es posible coadyuvar con tales objetivos.

Entre sus objetivos derivados están:

2.2.3.7. Consolidar el protagonismo popular en las manifestaciones culturales y deportivas, centrado en la creación de una conciencia generadora de transformaciones para la construcción del socialismo.

2.2.6. Propiciar las condiciones para el desarrollo de una cultura de recreación y práctica deportiva liberadora, ambientalista e integradora en torno a los valores de la Patria, como vía para la liberación de la conciencia, la paz y la convivencia armónica.

2.2.6.1. Profundizar la masificación deportiva.

2.2.6.2. Consolidar el Fondo Nacional del Deporte, Actividad Física y Educación Física para impulsar la masificación del deporte.

2.2.6.3. Ampliar la infraestructura de la Misión Barrio Adentro Deportivo y de todos los espacios deportivos a nivel parroquial.

2.2.6.4. Contribuir a la práctica sistemática, masiva y diversificada de la actividad física en las comunidades y espacios públicos.

2.2.6.5. Fortalecer el deporte de alto rendimiento, con apoyo integral al atleta y héroes del deporte, desarrollo de la medicina y las ciencias aplicadas al deporte de alto rendimiento, desarrollo de centros de alto rendimiento y de la escuela nacional de talentos deportivos.

2.2.7.1. Promover la ética socialista en los espacios de formación, recreación y ocio libre de los jóvenes, orientando ésta hacia la paz, la solidaridad, una vida sana y la convivencia comunal... 
2.3.4.6. Incorporar al Poder Popular en la recuperación y creación de espacios públicos para el desarrollo de actividades culturales, recreativas y preventivas, tales como las canchas de paz y otras de prevención y recreación en las comunidades.

\title{
Esperanzas olímpicas y paralímpicas
}

El programa de esperanzas olímpicas y paralímpicas contempla el desarrollo de los atletas que prefiguran como promesas olímpicas. Eduardo Álvarez Camacho, presidente del Comité Olímpico Venezolano (COV), en referencia a este programa (desarrollado con el MPPD), sostuvo:

\begin{abstract}
Hay varios requisitos para ser considerado candidato por las federaciones deportivas nacionales. La edad, el nivel atlético, si hay lesiones crónicas, la factibilidad de concentración dentro y fuera de Venezuela, si es estudiante y los estudios biomecánicos a los que debe ser sometido. Además, el atleta debe tener marcas de nivel, sin sanciones y someterse a exámenes anti doping (sec. 1/1).
\end{abstract}

\section{Atención social al atleta}

Se trata de un programa denominado Bienestar social integral al atleta de alto rendimiento. De acuerdo con el MPPD (2010), es un proyecto que,

[...] contempla acciones de apoyo en las áreas socioeconómica, educativa básica y profesional, recreativa y cultural, a los fines de contribuir a la formación integral de los atletas, y permitirles que cumplan con su preparación y sus compromisos deportivos en condiciones adecuadas (p. 48).

Entre estas acciones están: becas, bonos por rendimiento deportivo (medallas, posicionamiento, marcas deportivas), adjudicación de viviendas por metas, ayuda económica para adquisición y/o mejoramiento de viviendas, seguro Nacional e Internacional, HCM (hospitalización, cirugía y maternidad) para atletas, entrenadores y familiares, asistencia técnica deportiva durante el año, apoyo científico en los CENACADE, laboratorio de Biomecánica del IND, formación en lo referente al dopaje, apoyo a FUNDAEXAR. A ello se suma la posibilidad de estudios secundarios y universitarios con regímenes especiales tutoriales presenciales y semipresenciales, 
convenios con universidades nacionales, fortalecimiento de la Biblioteca del plan de lectura, reacondicionamiento del comedor del IND, cine-foro, clases de inglés, charlas educativas, así como presencia en actividades sociales, culturales y comunitarias (Ídem).

Entre otras acciones susceptibles de registro en el caso de las políticas públicas que, en materia de actividad física, deporte y recreación, ha desarrollado el Estado venezolano en el período, están: apoyo a deportes no olímpicos [como los deportes de motor (casos como el de Pastor Maldonado en la Fórmula-1), deportes extremo, deportes acuáticos extremo, culturismo, aerobismo, entre otros], apoyo al deporte profesional; desarrollo y recuperación de infraestructura deportiva. Según Cartaya (2014) el Estado trabajó en el:

\begin{abstract}
Desarrollo y descentralización de los Juegos Deportivos Nacionales, fueron albergadas las mejores ediciones históricas de Copa América 2007, además del Mundial de Béisbol femenino 2010, Mundial de Softbol femenino 2010, Iberoamericano de Atletismo 2012, Preolímpico de Baloncesto 2012, Premundial de Baloncesto 2013, al igual que tres eventos clasificatorios a los JJOO 2012 de natación, ciclismo y voleibol de playa, Suramericanos de Playa (sec. 1/1).
\end{abstract}

Moreno (2013), sostiene que el presidente Chávez “destinó una inversión monetaria sin precedentes en la historia venezolana" (sec. 1/1). Y, sosteniendo que hay inversiones que no fueron contempladas en los cálculos de 1999 a 2010 (por considerarse estadísticas hasta el momento en el que se ofrecieron las declaraciones), dice la periodista que, a eso habría que sumarle "lo invertido en la construcción o reparación de 1.885 infraestructuras deportivas (2.151.450.178,73 Bs., hasta 2011), lo destinado a la organización de eventos internacionales o las asignaciones especiales a atletas particulares" (Ídem). También deben sumarse 2 congresos científicos internacionales del ALBA, 4 congresos nacionales de medicina del deporte y 3 de biomecánica, se trabajó en la formación de 34.641 instructores deportivos comunales, 25.490 promotores integrales comunitarios y 50.000 promotores deportivos. Además, se 
desarrollaron 6.675 cursos de actualización científica y técnico deportiva, 2017 jornadas de actualización deportiva, se contaron 800 participantes en diplomados, cursos modulares y cursos de voceros comunales; 480 personas en el desarrollo de aspectos técnicos-científicos del entrenamiento deportivo, y se graduaron 405 estudiantes en la Universidad del Deporte. El MPPD ha realizado 350 congresos de las Unidades Educativas de Talento Deportivo, hay 320 institutos estadales y municipales en proyectos deportivos comunales, 240 personas se han formado y egresado de maestrías en actividad física y 336 en doctorado, se han desarrollado más de 120 jornadas internacionales científicas-pedagógicas, y finalmente se han creado 15 Centros Nacionales Aplicados al Deporte (Cenacade) (AVN, 2010c; sec. 1/1).

La AVN (2010d), reseña que en 2010 el Estado destinó la cifra de 505.713.094 bolívares en infraestructura deportiva; reparó, amplío y construyó instalaciones para los Juegos Deportivos Nacionales Cojedes 2003, Los Andes 2005, Los Llanos 2007, hizo reparaciones para los IX Juegos Estadales Escolares Yaracuy 2007 y los Juegos Deportivos Nacionales Municipales Lara 2007. Se hizo remodelación y ampliación en 3 estadios y la construcción de 6 estadios nuevos para la Copa América de Venezuela en 2007, con una inversión de \$1.200.000.000 (WRADIO, 2007). Se desarrolló el Programa Repara tu cancha, programa que apoyó a 200 consejos comunales con materiales de construcción y capacitación para que ellos mismos desarrollaran las obras. Además, la inversión en canchas múltiples entre 2002 y 2010, asciende a:

Tabla 5: Inversión en canchas múltiples 2002-2010.

\begin{tabular}{ccc}
\hline Año & Inversión (en Bs.) & Canchas \\
\hline 2002 & 6.468 .949 & 136 \\
2003 & 18.433 .264 & 361 \\
2004 & 18.352 .300 & 261 \\
2005 & 13.340 .705 & 302 \\
2006 & 498.826 .948 & 189 \\
2007 & $174.394 .909,93$ & 160 \\
2008 & 193.205 .682 & 123 \\
2009 & 484.830 .802 & 256 \\
2010 & 505.713 .094 & 71
\end{tabular}


Registro y Caracterización de las Políticas Públicas en Materia de Actividad Física, Deporte y Recreación en Venezuela (Período 1999-2014)

Alixon Reyes

\begin{tabular}{lrr} 
Total & $\mathbf{1 . 9 1 3 . 5 6 6 . 6 5 3 , 9 3}$ & $\mathbf{1 8 5 9}$ \\
\hline
\end{tabular}

Fuente: Elaboración propia.

Entre 2006 y 2007 se hizo la preparación para los Juegos Nacionales de Los Llanos, Copa América y Juegos del Alba. En 2010 se hizo la preparación para el Mundial de Softbol Femenino, en el Nuevo Estadio "La Independencia” y "El Bicentenario". Para el Mundial de Béisbol Femenino, se reacondicionaron los estadios "José Antonio Casanova", el estadio de la Aviación Militar en Maracay, y el estadio “César Nieves" de Catia La Mar. Además de la reparación y mantenimiento de 30 canchas a nivel nacional. Por todo esto y mucho más que ha escapado a los designios de este ejercicio, es que Da Silva (2010), sostiene: "Ningún gobierno ni institución pública o privada, jamás había realizado un esfuerzo comparable en materia deportiva y de actividad física” (p. 06). Y es básico, al cambiar el modelo, la lógica de atención a las políticas públicas en materia de actividad física, deporte y recreación, es transformada.

\section{Conclusiones}

Los resultados en materia de políticas públicas en actividad física, deporte y recreación entre 1999 y 2014 atestiguan avances. Pero ¿qué hace falta? En primer lugar, hacen falta estudios que permitan constatar con mayor asiduidad los sistemas de evaluación de las políticas públicas en el país, en relación con el tejido de políticas públicas en el marco general nacional (educación, salud, justicia, empleo, vivienda, previsión social, etc.); fortalecer los procesos de formación popular y específicos; articular con centros de investigación de las universidades con competencia en las materias en cuestión; consolidar equipos de académicos e investigadores en un consejo nacional asesor que, en articulación con equipos políticos, con equipos técnicos, con los movimientos sociales y colectivos, generen propuestas que permitan la evolución de las políticas públicas. Hace falta un sistema de contraloría público que permita garantizar la 
transparencia en la asignación y manejo de recursos, más la rendición de cuentas, entre otros elementos.

\section{REFERENCIAS}

AGENCIA Venezolana de Noticias. La masificación del deporte será uno de los puntos principales del plan de Pacificación Nacional, 2014. Disponible en línea: http://www.avn.info.ve/contenido/masificación-del-deporte-será-uno-puntosprincipales-del-plan-pacificación-nacional. Consultado el: 04 jan. 2015.

Censo Deportivo apuntalará masificación del deporte en Venezuela, 2010b. Disponible en línea: http://www.avn.info.ve/contenido/censo-deportivo-apuntalarámasificación-del-deporte-venezuela . Consultado el: 21 set. 2014.

AGENCIA Venezolana de Noticias. Venezuela vive una etapa de revolución en masificación deportiva, 2010c. Disponible en línea: http://www.avn.info.ve/node/34108?page=2. Consultado el: 12 dez. 2015.

Infraestructura deportiva alcanza niveles óptimos en Venezuela, 2010d Disponible en línea: http://www.avn.info.ve/contenido/infraestructura-deportivaalcanza-niveles-óptimos-venezuela . Consultado el: 15 abr. 2012.

ALTUVE, E. Revolución y política pública en ocio, tiempo libre y recreación: Venezuela durante el gobierno del presidente Hugo Chávez. Revista Educación Física y Deporte, v.31, n. 2, p. 975-986, 2012.

Metodología y análisis de la política pública. Propuestas: caso Venezuela (Deporte 1999-2010). Venezuela: Ediciones del Vicerrectorado de la Universidad del Zulia, 2011.

Deporte y revolución bolivariana en Venezuela (parte primera). Revista Acción Motriz, 1, p. 10-34, 2008.

BANCO Central de Venezuela (2014, 18 de marzo). Chávez fue el Presidente que más hizo por el deporte en Venezuela, 2014. Disponible en línea: http://www.bcv.org.ve/BLANKSITE/c4/notasprensa.asp?Codigo=11213\&Operacion=2 $\&$ Sec=False . Consultado el: 21 set. 2014.

CARTAYA, B. (2014). El deporte en Venezuela: la vida después de Chávez. Disponible en línea: http://semanario.info/deportes/295-el-deporte-en-venezuela-lavida-despues-de-chavez/\# . Consultado el: 16 jan. 015.

CEIMS del Ministerio del Poder Popular para las Relaciones Exteriores: Embajada de Venezuela en Argentina (2014). 1958: Fin de la dictadura y comienzo de una supuesta democracia. Disponible en: http://argentina.embajada.gob.ve/index.php?option=com_content\&id=808\%3A1958fin-de-una-dictadura-y-comienzo-de-una-supuesta-democracia\&Itemid=39\&lang=en Consultado el: 21 jan. 2015. 
CIUDAD Caracas. Ministro del Deporte invita a seguir aumentando cifra de clasificados a Londres, 2012. Disponible en línea: http://www.ciudadccs.info/?p=293731. Consultado el 08 nov. 2014.

CONSTITUCIÓN de la República Bolivariana de Venezuela. Gaceta Oficial N ${ }^{\circ} 5908$. Extraordinario de Fecha 15 de febrero de 2009.

DA SILVA, S. En Venezuela gana el deporte. Ministerio del Poder Popular para Comunicación e Información. Caracas: Venezuela, 2010.

DECRETO $\mathrm{N}^{\circ} 6367$ para la Creación de la Comisión Antidopaje de la República Bolivariana de Venezuela. Gaceta Oficial $N^{\circ} 39006$, de Fecha 01 de septiembre de 2008. República Bolivariana de Venezuela.

DECRETO para la Creación de la Agencia Antidopaje de la República Bolivariana de Venezuela (2004). República Bolivariana de Venezuela.

DEFENSORÍA del Pueblo. 27-F para siempre en la memoria de nuestro pueblo. Ministerio del Poder Popular para la Cultura: Venezuela, 2012.

ECURED (2014). Misión Barrio adentro deportivo. Disponible en línea: http://www.ecured.cu/index.php/Misión_Barrio_Adentro_Deportivo . Consultado el 12 dez. 2014.

FIGUEREDO G., J. M.; GONZÁLEZ M., I. L. Masificación deportiva en el contexto socialista bolivariano. Un reto del Ministerio del Poder Popular para el Deporte en el siglo XXI. Revista EFDeportes, v.18, n. 182, 2013.

INCRET. EI Instituto Nacional de Capacitación y Recreación de los Trabajadores. Disponible en línea: http://www.incret.gob.ve . Consultado el 13 dez. 2014.

JAUA, E. ¿Por qué Socialismo en Venezuela? Elementos para la batalla de ideas, 2015. Disponible en línea: http://www.psuv.org.ve/temas/noticias/elias-jaua-socialismovenezuela-conferencia-episcopal-chavez-rentismo-pobreza-unesco-fao-opinion/ Consultado el 21 jan. 2015.

LEY Orgánica de Recreación (2015). Gaceta Extraordinaria $\mathrm{N}^{\circ}$ 6.207, 28 de diciembre de 2015. República Bolivariana de Venezuela.

LEY para el Plan de la Patria 2013-2019. Gaceta Oficial $\mathrm{N}^{\circ}$ 6.118, de Fecha 04 de diciembre de 2013. República Bolivariana de Venezuela.

MINISTERIO del Poder Popular para el Deporte. Memoria y Cuenta 2013. Caracas, Venezuela, 2014

Fondo Nacional para el Desarrollo del deporte, la actividad física y la Educación Física, 2013. Disponible en línea: http://www.fondonacionaldeldeporte.gob.ve/fondo/index.php?option=com_wrapper\&vi ew=wrapper\&Itemid=413 . Consultado el 16 nov. 2014.

Plan Nacional de Deporte, Actividad Física y Educación Física 2013-2015. Caracas, Venezuela, 2012a. 
Memoria y Cuenta 2011. Caracas, Venezuela, 2012b.

Deporte, Actividad Física y Recreación. Gestión 2009. Ministerio del Poder Popular para el Deporte: Caracas, Venezuela, 2010.

MINISTERIO del Poder Popular para la Juventud y el Deporte . Misión y visión. Disponible en: http://www.mindeporte.gob.ve/ministerio/ . Consultado el: 17 jan. 2015.

MINISTERIO del Poder Popular para las Comunas y Protección Social. Gran Misión Recreación (Presentación Power Point). Venezuela, 2012.

MINGUS, R. El programa de la MUD. Análisis de los lineamientos de Gobierno de la Mesa de la Unidad Democrática. Imprenta Nacional \& Barrio Alerta: Caracas, Venezuela, 2012.

MORENO S. M. El deporte en la V República: inversión y control estatal, 2013. Disponible en línea: http://www.el-nacional.com/deportes/deporte-Republica-inversioncontrol-estatal_0_149987610.html.Consultado el 08 nov. 2014.

NUEVA Prensa. Primera reunión del Mercosur en materia deportiva en Venezuela, 2014. Disponible en línea: http://nuevaprensa.com.ve/Primera\%20reunión\%20del\%20Mercosur\%20en\%20materia \%20deportiva\%20en\%20Venezuela . Consultado el 21 jan. 2015.

OVIEDO, E. Coche celebró los 10 años de la Misión Adentro Deportivo, 2014. Prensa Mindeporte. Disponible en: http://www.mindeporte.gob.ve/noticia.php?id=523 . Consultado el: 18 dez. 2014.

PROCURADURÍA General de la República. Hace 7 años Venezuela fue sede de la final Argentina-Brasil de la Copa América, 2014. Disponible en línea: http://pgr.gob.ve/index.php?option=com_content\&view=article\&id=13558:hace-7anos-venezuela-fue-sede-de-la-final-argentina-brasil-de-la-copaamerica\&catid=88:actualidad\&Itemid=24 . Consultado el 13 dez. 2014.

RAMÍREZ, E.; BASTARDO, O. El programa "Barrio Adentro Deportivo", en, PRADO, J.; GONZÁLEZ, V. (Comp.). La Educación Física y el deporte en la República Bolivariana de Venezuela. Universidad de los Andes: Venezuela, 2007.

REYES, A. Políticas públicas en el marco de una nueva cultura de la recreación. Revista Humanartes, v. 4, n. 7,pp. 8-32, 2015.

Plan Nacional de Recreación para el Vivir Bien, 2011. Disponible en línea: http://www.aporrea.org/actualidad/a135293.html . Consultado el 24 ago. 2014.

ROJAS, E. El empujón del sambo, 2013. Disponible en línea: http://www.eluniversal.com/deportes/130816/el-empujon-del-sambo . Consultado el 11 dez. 2014.

TABARES, J. F.; MOLINA. V.; GERLERO, J.; BESTRAD, P.; LAZZAROTTI F., A.; DÍAS, C.; PAZ, e REYES, A. Producción de conocimiento en ocio, recreación y tiempo libre en américa latina. Licere, v. 17, n. 2, p. 192-221, 2014. 
TORREALBA, A.; ROJAS, M. V. Plan Nacional de Recreación para el Vivir Bien ofrece planes para Carnaval 2013. Disponible en línea: http://www.mpcomunas.gob.ve/plan-nacional-de-recreaciann-para/. Consultado el 26 ago. 2014.

ÚLTIMAS Noticias. Arrancó Plan Vacacional Comunitario en todo el país. Disponible en línea: https://www.ultimasnoticias.com.ve/noticias/ciudad/parroquias/arranco-planvacacional-comunitario-en-todo-el-pai.aspx\#ixzz3BSN2OUmK Consultado el 26 ago. 2014.

VIZCAYA, O. J.; SUÁREZ C. O. Reflexiones acerca de los rasgos esenciales de la política deportiva en Venezuela. Revista EFDeportes, v.20, n. 204, 2015. Disponible en línea: https://www.efdeportes.com/efd204/rasgos-de-la-politica-deportiva-envenezuela.htm . Consultado el 12 out. 2016.

WRADIO. Invierte Venezuela mil 200 mdd para Copa América 2007. Disponible en línea: http://wradio.com.mx/radio/2007/06/27/deportes/1182969600_445732.html Consultado el 12 out. 2015.

\section{Endereço do Autor:}

Alixon Reyes

Pasaje Villa el Bosque Casa n. 16

Las Mariposas, Km 12, Camino a Tanilvoro

Cillán - Chile

Endereço Eletrônico: alixonreyes@ unach.cl 